Departamento de Química Orgânica e Biológica

Diretor: Prof. Dr. Fonseca Ribeiro

\title{
DA AÇÃO DIURÉTICA DA CINARÍNA E DE SUA OBTENÇÃO EM ESTADO CRISTALÍNO
}

\section{J. F. Tabarelli Neto, Yaro Ribeiro Gandra e O. F. Ribeiro}

3 figuras no texto

O uso da alcachofra (Cynara scolymus) na terapeutica não é recente. Pela bibliografia verifica-se que êste vegetal foi estudado de vários pontos de vista: produz hipoglicemía (1 e 2) donde sua indicação aliás discutida, como alimento para os diabéticos (3 e 4) ; influencía o metabolismo do colesteról (5 a 7), e mostra outras propriedades farmacológicas, das quais as de maior interesse e melhor documentadas são as diurética e colagoga (5 a 11).

Êstes dois tipos de ação foram confirmados não só por trabalhos de laboratório como tambem na clínica, passando a alcachofra a ser aconselhada em certas afecções hepáticas e renais (12 e 13).

Nos trabalhos experimentais têm sido utilizados extratos da planta ou o princípio ativo cristalisado; segundo CHABRoL e colaboradores (9), êsse princípio atívo se acha presente em todas as partes da planta com exceção das bracteas florais que representam justamente a parte usada como alimento.

Entretanto não encontramos nenhuma descrição detalhada de técnica que permitisse obter o princípio atívo (cinarína) sob forma cristalisada e em estado de pureza.

Visando principalmente obter a substância cristalisada e documentar seu efeito farmacológico preparamos, de início, um extrato fluido, pela maceração de $300 \mathrm{gr}$. de alcachofra em pó em $1000 \mathrm{~cm} .^{3}$ de álcool a $70 \%$, por três dias consecutivos; a porção líquida, depois de aquecida para total eliminação do álcool e filtrada, forneceu-nos um líquido límpido de côr marron, dosando $22,25 \%$ de matéria sêca e cristalisando em cristais claros, porém acompanhados de muita impureza.

Com êste extrato, diluido ao terço em água distilada (resíduo sêco $7,41 \%$ ), fizemos uma prova de toxicidade em infusão lenta, registrando em traçado de acôrdo com o protocolo seguinte:

Cão de $12 \mathrm{~kg}$., previamente anestesiado pela cloralóse, depois de vagotomia bilateral, é submetido a injeção do líquido na veia femural, gota a gota, numa velocidade aproximada de $1 \mathrm{~cm} .{ }^{3}$ por minuto, até a morte do animal. No traçado da figura 1 fizemos registrar as variações que porventura podiam ser induzidas para o lado da pres- 
são arterial e da mecânica respiratoria. O método utilisado para a tomada da pressão sanguínea foi o habitual - o registro gráfico da pressão carotidiana por intermédio de um manometro de mercurio posto em comunicação por um sistema de tubos de borracha, torneiras e canulas, com uma das carotidas primitivas do animal. Para a verificação dos efeitos da ação da substância sôbre a frequência e a amplitude dos movimentos respiratórios usamos o pneumógrafo de Tournade, o qual era ligado por intermedio de um tubo de borracha à um tambor de Marey. Insuflado e regulado o ar dentro do sistema era o pneumógrafo fixado, segundo a técnica, sôbre o torax do animal cujos movimentos respiratórios faziam variar a pressão interna do sistema movimentando a haste inscritora do tambor.

PRESSÃO SANGUINEA E MOVIMENTOS RESPIRATORIOS

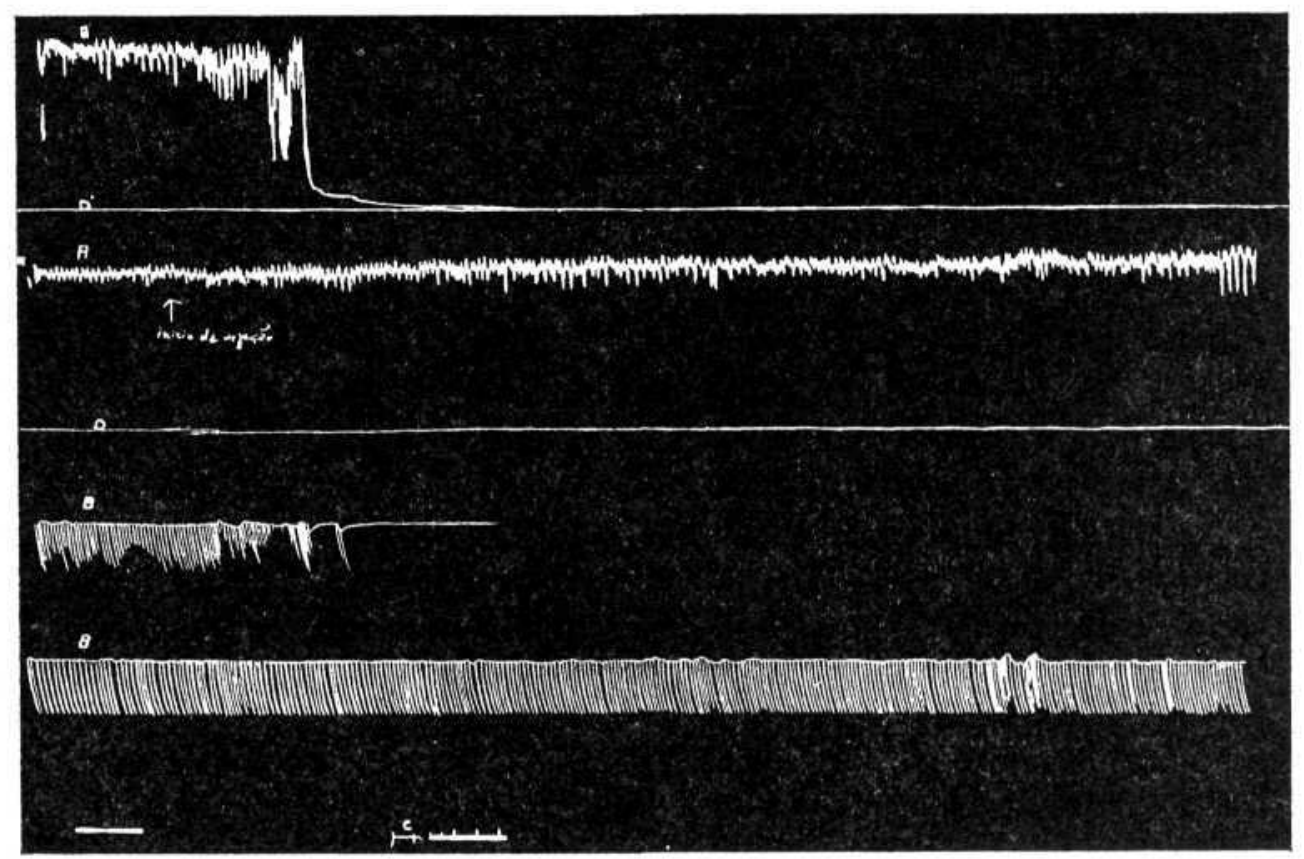

Figura 1

Cão $\sigma=12 \mathrm{Kg}$.

Anestesia pela cloralóse. Vagotomia bilateral.

$\mathbf{A}=$ traçado da pressão arterial, continuando em $\mathbf{A}^{\prime}$.

$\mathbf{B}=$ traçado dos movimentos respiratorios continuando em $\mathbf{B}^{\prime}$, o traçado ascendente representa a fase expiratoria.

D e $\mathrm{D}^{\prime}=$ linha zero.

$\mathrm{C}=$ tempo $1^{\prime}$. 
Sujeito a prova, o animal veiu a morrer depois de receber uma dose de $97 \mathrm{~cm} .^{3}$ da solução a $1 / 3$ do nosso extrato. Pelo traçado resultante desta experiência, pode-se verificar que mínimas foram as alterações sofridas pela pressão arterial e movimentos respiratórios, quer no rítmo, quer na amplitude, a não ser nas fases finais da intoxicação, na qual pode-se ainda notar que a parada do coração precedeu aquela da respiração. Pelo exposto, concluimos que a ação diurética do extrato poderia ser pesquisada, com a condição do mesmo ser injetado lentamente, e que tal efeito, se presente, independeria de modificações da pressão arterial.

A técnica usada foi a seguinte: anestesiado um cão de 10 quilos pela cloralóse após laparotomia na região pré-púbica, localisavamos e dissecavamos os dois uréteres; em seguida faziamos em cada um deles e na mesma altura uma abertura em $\mathrm{V}$, através da qual era introduzido e fixado um dos ramos de uma mesma canula de vidro em $\mathrm{Y}$; coletavamos assim por um único tubo a urina de ambos os ureteres.

\section{REOGRAFIA}

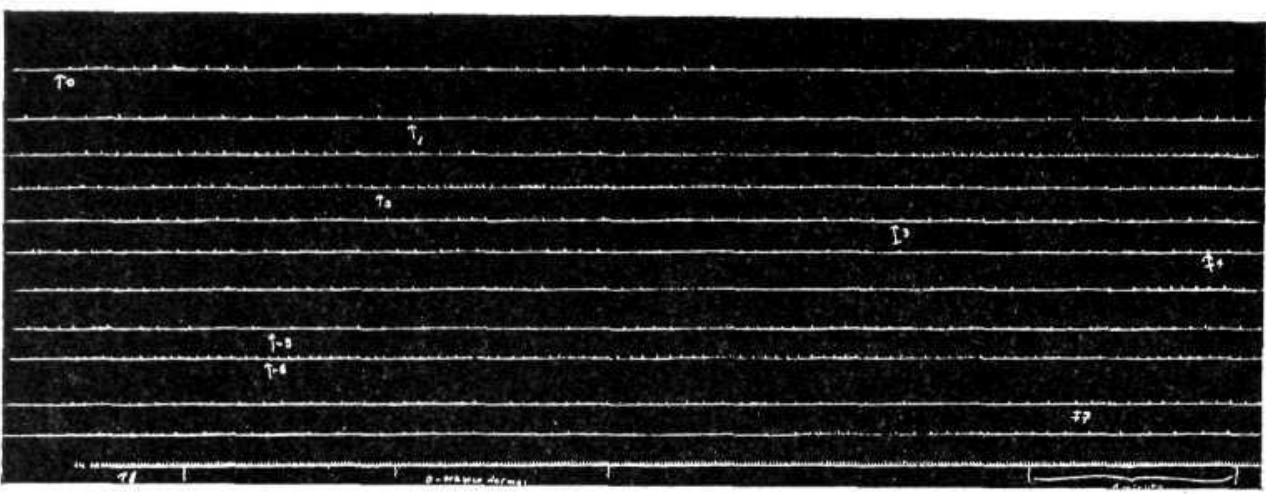

Figura 2

Cão $\sigma^{\pi}=10 \mathrm{~kg}$.

Anestesia pela cloralóse.

Em 0 = registro do escoamento normal.

" 1 = início da injeção endovenosa, de $15 \mathrm{cc}$. da solução ao terço, em agua distilada, do extrato.

$" 2$ = fim da injeção.

" 3 = início da injeção endovenosa, de 15 cc. de sôro fisiológico.

$" 4$ = fim da injeção.

" 5 = início da segunda injeção de $10 \mathrm{cc}$. da solução de prova.

$" 6$ = fim da injeção.

" 7 = Uma hora após ao início da experiencia.

$" 8=$ tempo $=1 "$. 
As gotas de urina na sua quéda, eram interceptadas por um tambor manipulador de Marey o qual achava-se associado por meio de um tubo de borracha a um tambor inscritor de Marey e Chaveau. Obtendo desse modo o registro gráfico das gotas, poderiamos avaliar a ação diurética da substância.

Pelo traçado da figura 2, resultante desta experiência, verifica-se a ação diurética do nosso extrato.

Após obter um traçado do escoamento normal, injetamos na veia femural do cão, - dissecada previamente e tendo a sua parte distal ligada - numa velocidade aproximada de $1 \mathrm{~cm}^{3}$ por minuto, $15 \mathrm{~cm}^{3}$ da solução ao terço do extrato fluido. $O$ efeito diurético manifestou-se mais ou menos no $4 .^{\circ}$ minuto após o início da injeção, acentuou-se progressivamente e perdurou ainda por cerca de 6 minutos após o término da mesma.

A marca de $\mathrm{n}^{\circ} 3$, no traçado corresponde a injeção, na mesma velocidade, de $15 \mathrm{~cm} .^{3}$ de sôro fisiológico, visando verificar se 0 efeito anterior não ocorrera a conta do volume líquido injetado, embora não fosse isso provável. Pelo traçado pode-se notar que não houve alteração digna de registro. Na marca de $n .^{\circ} 5$, afim de se obter uma contraprova, iniciamos a administração de $10 \mathrm{~cm} \cdot{ }^{3}$ da solução de prova feita tambem lentamente; ainda nêste caso notou-se a ação diurética, já verificada na primeira injeção.

Passamos a seguir às tentativas de purificação do princípio ativo e entre outras adotamos a seguinte técnica: 300 gramas de alcachofra em pó são maceradas em $1000 \mathrm{~cm}^{3}$ de água com $3 \%$ de ácido cloridrico e concentra-se em fogo diréto à metade do volume; filtra-se para retirar impurezas de aspecto resinoso que se precipitam e voltase a concentrar até $80-100 \mathrm{~cm}^{3}$; filtra-se de novo, precipita-se a cinarína pela adição de $250 \mathrm{~cm} \cdot{ }^{3}$ de álcool a $96^{\circ}$, na geladeira, decanta-se e lava-se os cristais com mais $150 \mathrm{~cm} .^{3}$ de álcool em 3 porções; seca$\mathrm{se}$, redissolvem-se os cristais em $50 \mathrm{~cm} .^{3}$ de água distilada, descora-se pela adição de carvão animal e o líquido incolor é deixado cristalisar. Os cristais brancos de cinarína são bastante soluveis em água, não reduzem o permanganato nem o Fehling, são oticamente inatívos e não se precipitam de suas soluções pelos vários cations. $\mathrm{O}$ rendimento equivale a 2-2.5\% sôbre o pêso do vegetal sêco. A análise desses cristais revela as seguintes características:

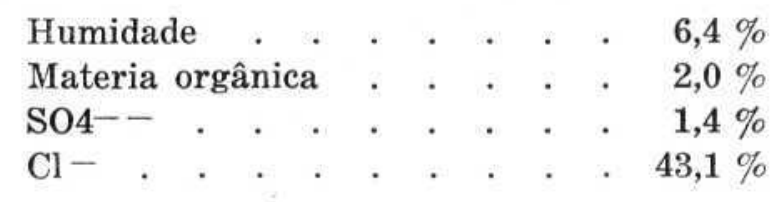




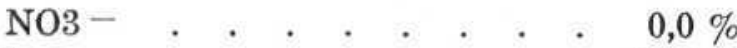

$$
\begin{aligned}
& \mathrm{K}+\text {. . . . . . . . . } 46,8 \% \\
& \mathrm{Na}+\text {. . . . . . . . . } 3,1 \%
\end{aligned}
$$

Com essa cinarína cristalisada repetimos a prova da diurése. Seguimos para tal, a mesma técnica descrita para a prova do extrato. Usamos aqui um cão, com o peso de $8 \mathrm{~kg}$.

Inscrito um traçado normal, figura n. ${ }^{\circ} 3$, injetamos na veia femural do cão, $0,1 \mathrm{gr}$. de cinarína, em solução a $3,5 \%$.

\section{REOGRAFIA}

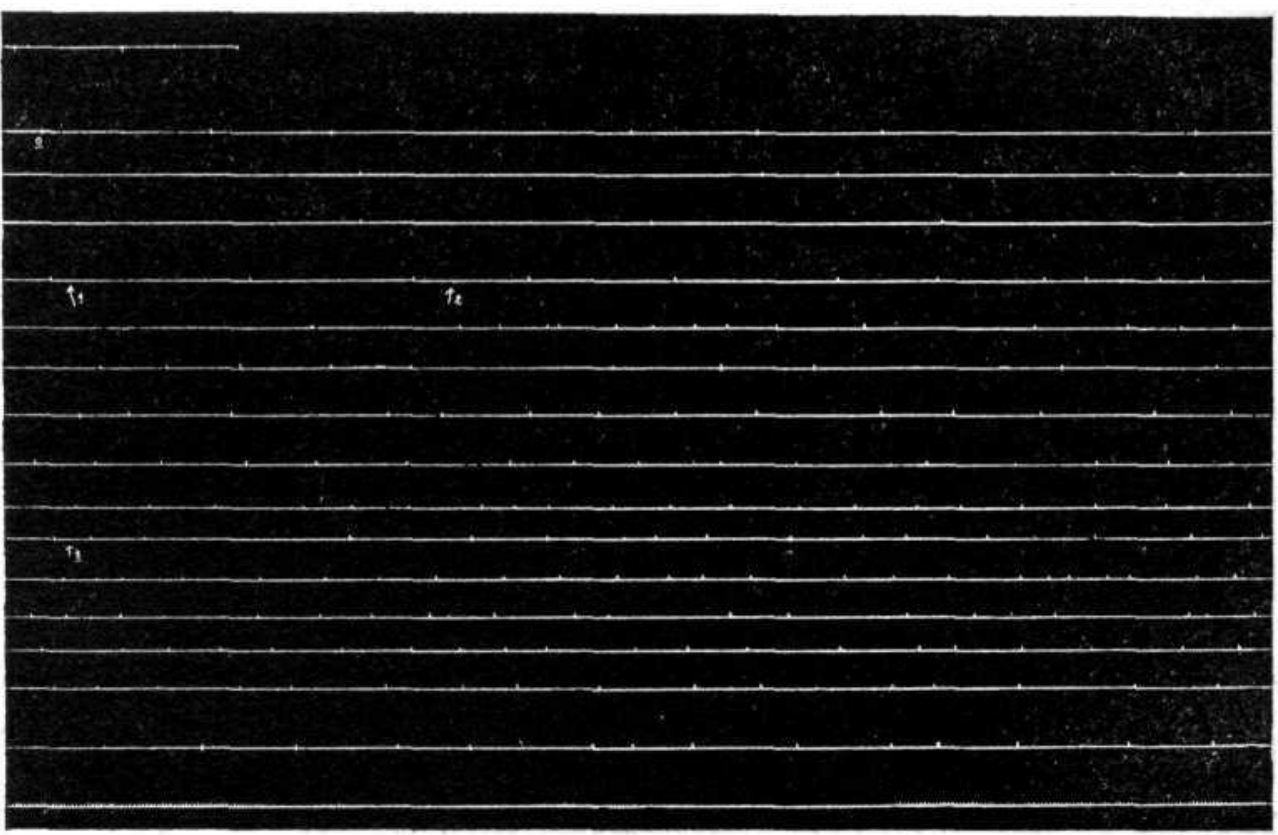

Cão $\sigma^{x}=8 \mathrm{~kg}$.

Figura 3

Anestesia pela cloralóse.

Em $0=$ registro do escoamento normal.

" 1 = início da injeção endovenosa de $0,1 \mathrm{gr}$. de cinarína em solução a $3,5 \%$.

$" 2$ = fim da injeção.

" $3=$ início da injeção intramuscular de $0,3 \mathrm{gr}$. de cinarína em solução a $3,5 \%$.

Tempo $=1 "$.

Verificou-se aqui tambem o efeito diurético, o qual perdurou por um espaço de tempo superior a 20 minutos. 
A seguir, quando o número de gotas de urina se aproximava do normal, fizemos uma segunda injeção da substância, na dose de 0,3 gr., agora porém, pela via intra-muscular. Nova ação diurética se evidenciou, com uma duração maior do efeito, como era de se esperar, verificando-se assim o mesmo tipo de ação no uso das vias endovenosa ou intramuscular para a administração da droga.

\section{RESUMO}

Os A.A. apresentam uma técnica simples para a extração e cristalisação do princípio atívo da alcachofra; o rendimento varía entre 2 e 2,5\% sôbre o pêso da planta sêca. Sob a forma de cinarína cristalisada e pura, o princípio atívo mantem suas propriedades farmacológicas; o efeito diurético é demonstrado pela inscrição, em gráfico, da urina interceptada nos uréteres, usando o cão como animal de experiência.

\section{Abstract}

The authors present a simple technique for the extraction and crystallization of the active principle of the artichoke (Cynara scolymus). The percentage varies between 2 and $2,5 \%$, on the weight of the dried plant. On the form of crystallised and pure cynarine, the active principle keeps its pharmacological properties. The diuretic effect is demonstrated by inscription in graphics, intercepting the urine in the ureters, the dog being the experiment animal.

\section{BIBLIOGRAFIA}

1 - RIsI, A. - 1933 - Prime richerche biologiche sull'azione ipoglicemizzante dell' -di "Cynara scolimus". Rass. ter. Pat. Clin. 5: 297-8.

2 - RISI, A. - 1939 - Hypoglucemic action of a oxidase extract of "Cynara scolymus". "in" Chemical Abstracts 33: 54969.

3 - Wescotr, L. E. - Wise, E. C. - 1929 - Failure of a diabetic patient to utilize dried artichoke powder. Arch. Internal. Med. 44: 362-7.

4 - Stein, H. B. - Longwell, B. B. - Lewis, R. C. - 1931 - The rôle of artichokes in the diet of the diabetic patient. Arch. Internal. Med. 48: 313-24.

5 - Rosa, G. E. - 1938 - Estudio farmacodinamico sobre el principio activo cristalisado del "Cynara scolymus" (aleachofra) y sus applicaciones en terapéutica hepatorrenal. Semana Med., Buenos Aires, 55 (22) : 1249-54.

6 - Tixier, L. - 1939 - Les actions physiologiques et thérapeutiques de "Cynara scolymus" (artichaut). Presse Med. 47: 880-83.

7 - Окамото, M. - 1941 - The effect of artichoke "Cynara scolymus" on liver and kidney function. I. The effect of an artichoke decoction on the so called catarrhal icterus. "In" Chemical Abstracts 35: 3323. 
J. F. Tabarelli Neto, Y. R. Gandra e O. F. Ribeiro - Ação diurét. da cinarína 117 8 - Ravina, A. - 1934 - L'action thérapeutique de la feuille d'artichaut et de son principe cristallisée. Presse Med. 65: 1299.

9 - Chabrol, E. - Charonnat, R. - Maximim, M. - Waitz, R. - 1931 Action cholérétique du "Cynara scolymus". Compt. rend. soc. biol. 108: 1020-22.

10 - Picard, R. - 1936 - Étude experimentale et clinique d'un principe active cristallisée du "Cynara scolymus". Presse med. 44: 1282.

11 - LOEPER - LEMAIRE - DANY - 1932 - La méthode stalagmométrique dans l'étude de certains cholérétiques. Progrès Medical (34): 1450-55.

12 - SÈzE, D. - 1934 - La feuille d'artichaut (Cynara scolymus) en thérapeutique. Progrès Medical (48): 1919-24.

13 - Trxier, L. - 1935 - L'emploi du "Cynara" en médicine infantile (son henreuse influence sur la stimulation des fonctions hépato-renais). Rev. Med. Française, 401-7. 